\title{
Desenvolvimento de Passalora sojina em diferentes meios de cultura e regimes luminosos
}

\section{Development of races of Passalora sojina on different substrates and light regimes}

\author{
Juliane Nicolodi Camera ${ }^{1}$, ; Carolina Cardoso Deuner ${ }^{3 *}$; \\ Anderson Luiz Durante Danelli'; Erlei Melo Reis ${ }^{5}$
}

\section{Resumo}

A mancha foliar "olho-de-rã" é uma doença que ocorre frequentemente na Argentina e no Brasil vem tornando-se importante em regiões produtoras de soja. A dificuldade em conseguir inóculo para estudos com $P$. sojina, levou ao desenvolvimento desse trabalho que teve como objetivos determinar a esporulação de raças $P$. sojina em diferentes meios de cultura e regimes luminosos e verificar diferença na esporulação das raças desse fungo. As placas com os meios de cultura BDA, STT, AI, V8 e FAA contendo as três raças de $P$. sojina foram submetidas ao fotoperíodo de 12/12 h (luz e escuro) e ao escuro. O delineamento experimental foi fatorial $5 \times 2 \times 3$ (meios de cultura, regimes luminosos, raças de P. sojina) com quatro repetições. O maior número de conídios $\mathrm{cm}^{-2}$ do fungo foi verificado para a raça 23 no meio de cultura STT e para as raças 24 e 25 no meio de cultura V8. A raça 25 do fungo, apresentou o maior número de conídios $\mathrm{cm}^{-2}$, independente do meio de cultura e do regime luminoso. Com relação ao regime luminoso, para todas as raças do fungo, as maiores esporulações foram verificadas no fotoperíodo de 12/12 h. Quando o fungo foi cultivado no meio de cultura AI, este apresentou a maior área da colônia, independente da raça do fungo e regime luminoso.

Palavras-chave: Substrato, fotoperíodo, mancha foliar "olho-de-rã"

\begin{abstract}
The leaf "frog-eye" spot is a disease that often occurs in Argentina and Brazil is becoming important in soy producing regions. The difficulty in achieving inoculum for studies with $P$. sojina led to the development of this work was to determine the sporulation of races $P$. sojina in different culture media and light regimes and check difference in sporulation of races of this fungus. The plates with the culture media BDA, STT , AI , V8 and FAA containing the three races of P. sojina were subjected to a photoperiod of 12/12 h (light and dark) and continuous dark. The experimental design was a factorial $5 \times 2 \times 3$ (culture medium, light regimes, races of $P$. sojina) with four replications. The greatest number of conidia $\mathrm{cm}^{-2}$ of the fungus was found for race 23 in the middle of STT culture and races 24 e 25 in the middle of V8 culture. The fungus race 25 , with the largest number of conidia $\mathrm{cm}^{-2}$, regardless of the medium and the light regimen. With respect to light regime for all races of the fungus, the largest esporulation were checked at a photoperiod of $12 / 12 \mathrm{~h}$. When the fungus was grown in culture medium AI, this had the largest area of the colony, regardless of breed fungus and light regime.
\end{abstract}

Key words: Substrate, photoperiod, leaf spot "frog-eye"

1 Este trabalho é parte da dissertação de mestrado da primeira autora.

2 Eng $^{\mathrm{a}}$ Agra , M.e do Laboratório de Fitopatologia, Universidade de Passo Fundo, UPF, Campus I, Passo Fundo, RS. E-mail: ju_camera@yahoo.com.br

3 Eng ${ }^{\mathrm{a}}$ Agr ${ }^{\mathrm{a}}$, Prof ${ }^{\mathrm{a}} \mathrm{Dr}^{\mathrm{a}}$ do Laboratório de Fitopatologia, UPF, Passo Fundo, RS. E-mail: carolinadeuner@upf.br

4 Eng ${ }^{\circ}$ Agr $^{\circ}$, M.e do Laboratório de Fitopatologia, UPF, Passo Fundo, RS. E-mail: andersondanelli@hotmail.com

5 Eng $^{\circ}$ Agr $^{\circ}$, Dr., Pesquisador da OR Melhoramento de Sementes Ltda., Passo Fundo, RS. E-mail: erleireis@upf.br

* Autor para correspondência 
A mancha "olho-de-rã" (Passalora sojina (Hara) H.D. Shin e Braun (1996), anteriormente denominada Cercospora sojina Hara 1915 é uma das principais doenças foliares na cultura da soja na Argentina e devido à produção e/ou importação de soja desse país, tem potencial para se tornar uma grande epidemia no Brasil. A primeira ocorrência da doença foi relatada na safra 1970/71 no Estado do Paraná (YORINORI, 1971) e posteriormente no Rio Grande do Sul (REIS; KIMATI, 1973). Na década de 70, a introdução de semente de cultivares suscetíveis na Região Sul resultou em danos que chegaram a $100 \%$ em diversas lavouras. Essa doença foi responsável por grandes perdas de soja no Brasil, mas atualmente, devido à utilização de cultivares resistentes tem sido esporádica e limitada a algumas regiões, sendo que até o momento, vinte e cinco raças do patógeno já foram descritas no Brasil (YORINORI; KLINGELFUSS, 2000).

A dificuldade em conseguir isolados esporulantes, ou mesmo padronizar condições ideais para a esporulação de fungos fitopatogênicos tem limitado o estudo de muitos patossistemas. Sabe-se que, tanto a quantidade como a qualidade da luz pode afetar a taxa de crescimento vegetativo, a indução da formação de estruturas reprodutivas, a pigmentação e a forma e o tamanho de grande parte das estruturas fúngicas. Devido a isso, vários trabalhos visando obter crescimento e esporulação de fungos em meios de cultura e regimes luminosos vêm sendo desenvolvidos em diferentes patossistemas (TEIXEIRA et al., 2001; BRUNELLI et al., 2006; CRUZ; PRESTES; MACIEL, 2009; MELO; REIS, 2010). No patossistema P. sojinasoja, ainda não existem essas informações. Com relação ao regime luminoso, a radiação luminosa pode induzir, inibir ou ter efeito neutro sobre o crescimento e a esporulação dos fungos, sendo que a luz estimula a reprodução assexual e sexual na maioria dos fungos, e seu efeito está intimamente relacionado à nutrição e à temperatura (TEIXEIRA et al., 2001). A maioria dos fungos sensíveis à luz, esporula quando expostos à luz contínua, mas alguns, chamados de esporuladores diurnos, requerem um período no escuro para iniciar a esporulação. Alguns fungos necessitam de luz para iniciar a formação de conidióforo e a esporogênese, entretanto, a esporulação é inibida pela luz (DHINGRA; SINCLAIR, 1995). Por outro lado, alguns fungos têm sua esporulação inibida pela ausência de luz (PULZ; MASSOLA; NELSON, 2009; MELO; REIS, 2010).

Além disso, um equilíbrio apropriado entre nutrientes no meio de cultura é um fator importante para o crescimento e esporulação de fungos (LILLY; BARNETT, 1951). Alguns meios de cultura apresentam maior riqueza nutricional e maior quantidade de carboidratos complexos, afetando assim, a esporulação de alguns fungos (STRANDBERG, 1987). Muitos utilizam glicose como fonte de carbono (CARLILE; WATKINSON, 1994) e o nitrogênio prontamente assimilável é indispensável para o desenvolvimento fúngico (GARRAWAY; EVANS, 1984), dentre outras substâncias fundamentais para o crescimento do mesmo.

Apesar do grande número de espécies do gênero Cercospora conhecidas, existem poucos estudos do crescimento desse fungo em cultivos artificiais. Existe um consenso de que essas espécies fúngicas apresentam, como características comuns, crescimento lento e escassa ou nula esporulação em meios de cultivo utilizados rotineiramente em laboratório (BLANEY, 1987; BRUNELLI et al., 2006).

Os objetivos desse trabalho foram verificar a esporulação das raças de $P$. sojina em diferentes meios de cultura e regimes luminosos e observar diferenças na esporulação das raças desse fungo.

O trabalho foi realizado no Laboratório de Fitopatologia da Faculdade de Agronomia e Medicina Veterinária da Universidade de Passo Fundo (UPF), no período de outubro a dezembro de 2010. 
As raças 23, 24 e 25 de $P$. sojina utilizados nesse trabalho foram fornecidos pela Embrapa Soja, e foram preservados em óleo mineral e em água esterilizada (ALFENAS; MAFIA, 2007) na micoteca do Laboratório de Fitopatologia da UPF. A raça 23 foi isolada do cultivar de soja Doko (Niquelândia-GO), a raça 24 , do cultivar de soja BRS 28 (Santa Filomena-PI) e raça 25, do cultivar de soja Cariri (Balsas-MA). A identificação das raças do fungo foi realizada através de cultivares diferenciadoras (YORINORI; KLINGELFUSS, 2000). Para utilização nos experimentos, realizouse o isolamento monospórico (ALFENAS; MAFIA, 2007) das três raças de P. sojina.

Os meios de cultura utilizados nesse trabalho foram: 1) Farinha de aveia ágar (FAA) - $40 \mathrm{~g}$ de farinha de aveia, $18 \mathrm{~g}$ de ágar, 0,2 $\mathrm{g}$ estreptomicina, 1 L água (FERNANDEZ, 1993); 2) Suco de tomate temperado (STT) - $200 \mathrm{~mL}$ de suco de tomate Super Bom ${ }^{\circledR} ; 16 \mathrm{~g}$ de ágar; 3,2 g de $\mathrm{CaCO}_{3}$, 0,2 $\mathrm{g}$ de estreptomicina e $800 \mathrm{~mL}$ de água destilada (TUITE, 1969); 3) Suco V8 ágar (V8) - 200 mL suco V8, produto de Campbell SoupCo. ${ }^{\circledR}, 3 \mathrm{~g}$ de $\mathrm{CaCO}_{3}, 15 \mathrm{~g}$ de ágar, 0,2 $\mathrm{g}$ de estreptomicina, $1 \mathrm{~L}$ de água destilada (TUITE, 1969); 4) Alimento infantil (AI) - $10 \mathrm{~g}$ de alimento infantil, produto de Nestlé Brasil Ltda ${ }^{\circledR}, 18 \mathrm{~g}$ de ágar, 0,2 $\mathrm{g}$ de estreptomicina, 1 L de água destilada (ALMEIDA; YAMASHITA, 1976) e 5) Batata sacarose ágar (BSA) (ALFENAS; MAFIA, 2007).

Após o preparo, os meios de cultura foram autoclavados a $121{ }^{\circ} \mathrm{C}$ por 20 minutos e vertidos assepticamente em placas de petri de polietileno $(60 \times 15 \mathrm{~mm})$. Foram preparadas oito placas para cada um dos meios de cultura, sendo que no centro de cada placa, depositou-se um disco de micélio de 4,68 $\mathrm{mm}$ de diâmetro do fungo crescido por vinte e cinco dias, obtido do isolamento monospórico. Em seguida, quatro placas de cada meio de cultura foram submetidas ao fotoperíodo de 12//12 h e ao escuro contínuo.

Os tratamentos foram distribuídos ao acaso na câmara de crescimento com lâmpadas fluorescentes OSRAM ${ }^{\circledR}$ Universal, 40 watts, a $25{ }^{\circ} \mathrm{C}$ por vinte e cinco dias. Decorrido esse tempo, procedeu-se a quantificação da esporulação e a medição da área da colônia. Para a quantificação dos conídios do fungo, foram adicionados $5 \mathrm{~mL}$ de água destilada na placa de petri e com o auxílio de um pincel, os conídios foram removidos. A partir da suspensão de esporos, coletou-se $1 \mathrm{~mL}$, e em seguida contou-se o número de conídios em hemacitômetro tipo Neubauer (ALFENAS; MAFIA, 2007). Foi calculado o número de conídios $\mathrm{cm}^{-2}$, com base no número de conídios $\mathrm{mL}^{-1} \mathrm{e}$ a área da colônia. Para a medição de área das colônias utilizou-se um paquímetro digital.

O delineamento experimental foi inteiramente casualizado, com arranjo fatorial triplo $3 \times 5 \times 2$ (raças de $P$. sojina $\mathrm{x}$ meios de cultura $\mathrm{x}$ regimes luminosos), com quatro repetições. O número de conídios $\mathrm{cm}^{-2}$ e a área das colônias foram submetidos à análise da variância e ao teste de comparação de médias por Tukey 5\%.

Para a variável número de conídios $\mathrm{cm}^{-2}$, houve interação significativa entre os três fatores analisados. Para a interação entre raças de $P$. sojina e meios de cultura, observou-se que, o maior número de conídios $\mathrm{cm}^{-2}$ do fungo foi verificado para a raça 25 , independente dos meios de cultura utilizados (Tabela 1). As menores esporulações de $P$. sojina foram verificadas para os meios de cultura AI e FAA, no qual as raças 23 e 24 de fungo foram estatisticamente semelhantes entre si e inferior à raça 25. Para o meio de cultura STT e BDA, a raça 24 foi estatisticamente inferior às demais raças, apresentando menor esporulação. Comportamento semelhante ao do meio de cultura STT foi verificado para a raça 23 no meio V8.

A raça 23 de $P$. sojina, apresentou maior número de conídios $\mathrm{cm}^{-2}$ no meio de cultura STT, diferindo estatisticamente dos demais tratamentos e menor esporulação no meio de cultura FAA (Tabela 1). Para a raça 24 , verificou-se o maior número de conídios $\mathrm{cm}^{-2}$ no meio de cultura V8 e menor esporulação 
nos meios BDA e FAA, sendo esses dois últimos estatisticamente iguais. Para a raça 25, observou-se que a maior esporulação ocorreu no meio de cultura $\mathrm{V} 8$, sendo que, o menor número de conídios $\mathrm{cm}^{-2}$ foi observado no meio BDA.
Para a interação raças de $P$. sojina e regimes luminosos, a maior produção de esporos foi obtida em condições de fotoperiodo $12 / 12 \mathrm{~h}$ (Tabela 2). A raça 25 do fungo, apresentou os maiores valores de conídios $\mathrm{cm}^{-2}$, independente do regime luminoso e o menor número de conídios $\mathrm{cm}^{-2}$ foi verificado para a raça 23 no escuro.

Tabela 1. Números de conídios $\mathrm{cm}^{-2}$ das raças 23, 24 e 25 de Passalora sojina em diferentes meios de cultura. Passo Fundo, RS. 2011.

\begin{tabular}{|c|c|c|c|c|c|}
\hline \multirow{2}{*}{ Raças } & \multicolumn{5}{|c|}{ Meios de cultura } \\
\hline & $\mathrm{AI}^{1}$ & STT $^{2}$ & $\mathrm{BSA}^{3}$ & $\mathrm{~V}^{4}$ & FAA $^{5}$ \\
\hline 23 & B $4208,8 b^{6}$ & A 8402,8 b & D 1026,3 a & C $2418,1 \mathrm{c}$ & E $444,1 b$ \\
\hline 24 & B 4227,8 b & C $3414,8 \mathrm{c}$ & D $677,7 \mathrm{~b}$ & A $9255,0 \mathrm{~b}$ & D $411,7 \mathrm{~b}$ \\
\hline 25 & C 8214,9 a & B 11243,1 a & E $1344,0 \mathrm{a}$ & A $17529,1 \mathrm{a}$ & D $3837,2 \mathrm{a}$ \\
\hline $\mathrm{CV} \%$ & \multicolumn{5}{|c|}{10,91} \\
\hline
\end{tabular}

${ }^{1}$ AI: Alimento infantil; ${ }^{2}$ STT: Suco de tomate temperado; ${ }^{3}$ BSA: Batata sacarose ágar (BSA); ${ }^{4}$ V8: Suco V8 ágar; ${ }^{5}$ FAA: Farinha de aveia ágar; ${ }^{6}$ Médias seguidas por mesmas letras minúscula na coluna e maiúscula na linha, não diferem entre si pelo teste de Tukey a $5 \%$ de probabilidade do erro.

Fonte: Elaboração dos autores.

Tabela 2. Números de conídios $\mathrm{cm}^{-2}$ das raças 23, 24 e 25 de Passalora sojina em diferentes regimes luminosos. Passo Fundo, RS. 2011.

\begin{tabular}{clc}
\hline Raças & Escuro $^{1}$ & Fotoperíodo $^{2}$ \\
\hline 23 & B $137,8 \mathrm{c}^{3}$ & A 6462,2 b \\
24 & B 540,0 b & A 6734,8 b \\
25 & B 1061,5 a & A 15805,8 a \\
\hline CV \% & & \\
\hline
\end{tabular}

${ }^{1}$ Escuro contínuo; ${ }^{2}$ Fotoperíodo 12 horas de luz e 12 horas de escuro. ${ }^{3}$ Médias seguidas por mesmas letras minúscula na coluna e maiúscula na linha, não diferem entre si pelo teste de Tukey a 5\% de probabilidade do erro;

Fonte: Elaboração dos autores.

Para a interação entre meios de cultura e regimes luminosos, o maior número de conídios $\mathrm{cm}^{-2}$ foi verificado quando o fungo foi incubado no fotoperíodo de 12/12 h (Tabela 3), sendo este estatisticamente superior às placas incubadas no escuro, independente do meio de cultura utilizado. A maior produção de esporos $\mathrm{cm}^{-2}$ foi obtida no meio V8 no fotoperíodo $12 / 12 \mathrm{~h}$ e a menor no meio BDA e AI no escuro contínuo.

Com relação à área das colônias, houve interação significativa entre raças de $P$. sojina e meios de cultura, e para meios de cultura e regimes luminosos. Para a primeira interação, observou-se que independente da raça de $P$. sojina, o meio de cultura AI apresentou a maior área da colônia e o meio de cultura STT, a menor (Tabela 4). A raça 23 apresentou a maior área das colônias nos meios de cultura STT, BDA e V8. O mesmo comportamento foi verificado para a raça 24 nos meios de cultura V8 e FAA e para a raça 25 nos meios de cultura AI, BDA, V8 e FAA. Para a interação meios de cultura e regimes luminosos, o meio de cultura AI apresentou a maior área da colônia, independente do regime 
luminoso (Tabela 5). As menores áreas de colônias do fungo foram verificadas para o meio de cultura STT e BDA quando as placas foram incubadas no escuro continuo e para o STT no fotoperíodo de 12/12 h. Os meios de cultura AI, BDA, V8 e FAA apresentaram maior área de colônia (Tabela 5), quando as placas com o fungo foram incubadas no fotoperíodo de 12/12 h e o meio de cultura STT quando as placas foram incubadas no escuro. Os dados encontrados neste foram semelhantes aos encontrados por Brunelli et al. (2006), com C. zeaemaydis, relataram-no qual, a melhor condição de incubação visando à produção de conídios ocorreu no regime de 12/12 h (luz/escuro).

Tabela 3. Números de conídios $\mathrm{cm}^{-2}$ de Passalora sojina em diferentes meios de cultura e regimes luminosos. Passo Fundo, RS. 2011.

\begin{tabular}{cll}
\hline Meios de cultura & Escuro $^{6}$ & Fotoperíodo $^{7}$ \\
\hline AI $^{1}$ & B 206,14 c & A 10894,96 c \\
STT $^{2}$ & B 720,46 b & A 14653,44 b \\
BSA $^{3}$ & B 7,218 c & A 2158,15 d \\
V8 $^{4}$ & B 1196,63 a & A 18271,60 a \\
FAA $^{5}$ & B 768,63 ab & A 2360,10 d \\
\hline CV $\%$ & 8,76 & \\
\hline
\end{tabular}

${ }^{1} \mathrm{AI}$ : Alimento infantil; ${ }^{2} \mathrm{STT}$ : Suco de tomate temperado; ${ }^{3} \mathrm{BSA}$ : Batata sacarose ágar (BSA); ${ }^{4}$ V8: Suco V8 ágar; ${ }^{5} \mathrm{FAA}$ : Farinha de aveia ágar; ${ }^{6}$ Escuro contínuo; ${ }^{7}$ Fotoperíodo 12 horas de luz e 12 horas de escuro; ${ }^{8}$ Médias seguidas por mesmas letras minúscula na coluna e maiúscula na linha, não diferem entre si pelo teste de Tukey a 5\% de probabilidade do erro.

Fonte: Elaboração dos autores.

Tabela 4. Área da colônia $\left(\mathrm{cm}^{2}\right)$ das raças 23, 24 e 25 de Passalora sojina em diferentes meios de cultura. Passo Fundo, RS. 2011.

\begin{tabular}{|c|c|c|c|c|c|}
\hline \multirow{2}{*}{ Raças } & \multicolumn{5}{|c|}{ Meios de cultura } \\
\hline & $\mathrm{AI}^{1}$ & $\mathrm{STT}^{2}$ & $\mathrm{BSA}^{3}$ & $\mathrm{~V}^{4}$ & FAA $^{5}$ \\
\hline 23 & A $14,9 b^{6}$ & $\mathrm{C} 11,7 \mathrm{a}$ & $\mathrm{C} 12,1 \mathrm{a}$ & B 12,9 a & B $12,9 \mathrm{~b}$ \\
\hline 24 & A 15,2 b & E $10,7 b$ & D $11,3 \mathrm{~b}$ & C $12,8 \mathrm{a}$ & B 13,5 a \\
\hline 25 & A 15,8 a & D $10,7 \mathrm{~b}$ & C $12,2 \mathrm{a}$ & $\mathrm{C} 12,5 \mathrm{a}$ & B 13,8 a \\
\hline CV \% & \multicolumn{5}{|c|}{3,47} \\
\hline
\end{tabular}

${ }^{1} \mathrm{AI}$ : Alimento infantil; ${ }^{2} \mathrm{STT}$ : Suco de tomate temperado; ${ }^{3} \mathrm{BSA}$ : Batata sacarose ágar (BSA); ${ }^{4}$ V8: Suco V8 ágar; ${ }^{5} \mathrm{FAA}$ : Farinha de aveia ágar; ${ }^{6}$ Médias seguidas por mesmas letras minúscula na coluna e maiúscula na linha, não diferem entre si pelo teste de Tukey a $5 \%$ de probabilidade do erro.

Fonte: Elaboração dos autores.

Tabela 5. Área da colônia $\left(\mathrm{cm}^{2}\right)$ do fungo Passalora sojina em diferentes meios de cultura e regimes luminosos. Passo Fundo, RS. 2011.

\begin{tabular}{|c|c|c|c|c|c|}
\hline \multirow{2}{*}{$\begin{array}{l}\text { Regime } \\
\text { luminoso }\end{array}$} & \multicolumn{5}{|c|}{ Meios de cultura } \\
\hline & $\mathrm{AI}^{1}$ & $\mathrm{STT}^{2}$ & $\mathrm{BSA}^{3}$ & $\mathrm{~V}^{4}$ & FAA $^{5}$ \\
\hline Escuro $^{6}$ & B $14,9 \mathrm{a}^{8}$ & A $11,4 d$ & B $11,5 \mathrm{~d}$ & B $12,5 \mathrm{c}$ & B $13,1 \mathrm{~b}$ \\
\hline Fotoperíodo 7 & A 15,7 a & B $10,7 \mathrm{e}$ & A $12,2 \mathrm{~d}$ & A $12,9 \mathrm{c}$ & A 13,8 b \\
\hline CV \% & \multicolumn{5}{|c|}{4,55} \\
\hline
\end{tabular}

${ }^{1} \mathrm{AI}$ : Alimento infantil; ${ }^{2} \mathrm{STT}$ : Suco de tomate temperado; ${ }^{3} \mathrm{BSA}$ : Batata sacarose ágar (BSA); ${ }^{4}$ V8: Suco V8 ágar; ${ }^{5} \mathrm{FAA}$ : Farinha de aveia ágar; ${ }^{6}$ Escuro contínuo; ${ }^{7}$ Fotoperíodo 12 horas de luz e 12 horas de escuro; ${ }^{8}$ Médias seguidas por mesmas letras minúscula na coluna e maiúscula na linha, não diferem entre si pelo teste de Tukey a 5\% de probabilidade do erro.

Fonte: Elaboração dos autores. 
Com relação aos meios de cultura, segundo Hanada, Gasparotto e Pereira (2002), a maior esporulação de Paracercospora fijiensis (Morelet) Deighton foi verificada no meio V8, tanto no fotoperíodo quando no regime de luz sequencial. Esses mesmos autores relataram que não houve esporulação desse fungo no escuro para a maioria dos meios de cultura. Fato semelhante foi verificado no trabalho de Brunelli et al. (2006), no qual, os meios de cultura V8 e STT no fotoperíodo 12/12 h foram os que apresentaram melhor indução de esporulação, resultando na produção de $22,4 \times 10^{4}$ conídios $\mathrm{mL}^{-1} \mathrm{e}$ $28,62 \times 10^{4}$ conídios $\mathrm{mL}^{-1}$, respectivamente.

Para outras espécies do gênero Cercospora, há relatos indicando o efeito positivo sobre a esporulação da exposição à luz, em regimes alternados com períodos de escuro. Isso foi relatado em isolados de C. arachidicola por Moraes e Salgado (1997), de Cercospora zeae-maydis Tehon e Daniels por Beckman e Payne (1983) e em Cercospora kikuchii por Dela-Cueva, Natural e Hautea (1995). A inibição parcial da esporulação sob condições de escuro contínuo foi observada por Kilpatrick e Johnson (1956) para C. nicotianae Ellis e Everh, para Cercospora arachidicola Hori por Stavely e Nimmo (1969) e para P. fijiensis por Hanada, Gasparotto e Pereira (2002).

Uma das características das espécios do gênero Cercospora é o crescimento lento e a escassez de esporulação em meios artificiais (BRUNELLI et al., 2006). Segundo Veiga e Kimati (1974), os meios de cultura suco V8 e FAA foram os melhores para a esporulação de $P$. sojina. Os resultados obtidos no presente trabalho indicam que os meios de cultura V8 e STT, sendo o último uma modificação do V8, permitiram boa esporulação para o fungo $P$. sojina. $\mathrm{O}$ meio FAA não apresentou boa esporulação, apesar de ser o segundo melhor substrato para crescimento do fungo (Tabela 1 e 4). Os meios de cultura V8 e extrato de tomate (variação do meio V8) (HINE; ARAGAK, 1963) são aqueles que apresentam maior riqueza nutricional e maior quantidade de carboidratos complexos. Estas características são citadas por diversos autores como capazes de induzir a reprodução de muitos fungos mitospóricos (LUKENS, 1963; STRANDBERG, 1987). O meio de cultura V8 é relatado como bom indutor de esporulação em várias espécies do gênero Cercospora (BECKMAN; PAYNE, 1963; HANADA; GASPAROTTO; PEREIRA, 2002). O meio de cultura extrato de tomate foi indicado por Queiroz e Menezes (1993), como capaz de induzir formação de esporos em Cercospora nicotianae Ellis e Everh. Comparando ambos os meios, o extrato de tomate mostrou-se mais vantajoso do ponto de vista prático, uma vez que o mesmo é composto por um produto nacional que se consegue facilmente no comércio.

As maiores esporulações de $P$. sojina ocorrem quando o fungo é incubado em fotoperíodo 12/12 h (luz/escuro).

A raça 25 de $P$. sojina apresenta maior número de conídio $\mathrm{cm}^{-2}$, independente do meio de cultura e do regime luminoso.

$\mathrm{O}$ maior número de conídio $\mathrm{cm}^{-2}$ de $P$. sojina é verificado para a raça 23 no meio de cultura STT e para as raças 24 e 25 no meio de cultura V8.

$\mathrm{O}$ fungo cultivado em meio de cultura AI apresenta a maior área da colônia, independente da raça e regime luminoso, porém, não há relação entre maior área da colônia com maior esporulação de $P$. sojina.

Existe diferença de crescimento e esporulação entre as raças 23,24 e 25 de $P$. sojina.

\section{Agradecimento}

À pesquisadora Claudine Dinali Santos Seixas da Embrapa Soja, Londrina-PR, pelo fornecimento das raças de $P$. sojina. 


\section{Referências}

ALFENAS, A. C.; MAFIA, R. G. Métodos em fitopatologia. Viçosa: Editora UFV, 2007. 382 p.

ALMEIDA, A. M. R.; YAMASHITA, J. Crescimento e esporulação de Corynespora cassiicola (Berk. \& Curt.) Wei em diferentes meio de cultura. Fitopatologia Brasileira, Brasília v. 1, n. 1, p. 203-206, 1976.

BECKMAN, P. M.; PAYNE, G. A. Cultural techniques and conditions influencing growth and sporulation of Cercospora zeae-maydis and lesions development in corn. Phytopathology, Saint Paul, v. 73, n. 3, p. 286-289, 1983.

BLANEY, C. L. Fungal pathogens with potential for biocontrol of yellow nutsedge (Cyperus esculentus L.). 1987. Dissertation (Master of Science) - North Carolina State University, Raleigh, N.C.

BRUNELLI, K. R.; FAZZA, A. C.; SOBRINHO, C. A.; CAMARGO, L. E. A. Efeito do meio de cultura e do regime de luz na esporulação de Cercospora zeaemaydis. Summa Phytopathologica, Botucatu, v. 32, n. 1, p. 92-94, 2006.

CARLILE, M. J.; WATKINSON, S. C. The fungi. San Diego: Academic, 1994. 428 p.

CRUZ, M. F. A.; PRESTES, A. M.; MACIEL, J. L. N. Esporulação de Pyricularia grisea em diferentes meios de cultura e regimes de luz. Ciência Rural, Santa Maria, v. 39 , n. 5, p. 1562-1564, 2009.

DELA-CUEVA, F. M.; NATURAL, M. P.; HAUTEA, R. A. Cultural requirements for maximum conidial production of Cercospora kikuchii, the cause of purple seed stain of soybean. Philippine Phytopathology, Manila, v. 31, n. 1, p. 20-26, 1995.

DHINGRA, O. D.; SINCLAIR, J. B. Basic plant pathology methods. Boca Raton: CRC Press, 1995. 355 p.

FERNANDEZ, M. R. Manual para laboratório de fitopatologia. Passo Fundo: Embrapa-CNTP, 1993. 128 p.

GARRAWAY, M. O.; EVANS, R. C. Vitamins and growth factors. In: GARRAWAY, M. O.; EVANS, R. C. (Ed.). Fungal nutrition \& physiology. 2. ed. New York: John Willey. 1984. p. 171-212.

HANADA, R. E.; GASPAROTTO, L.; PEREIRA, J. C. R. Esporulação de Mycosphaerella fijiensis em diferentes meios de cultura. Fitopatologia Brasileira, Lavras, v. 27, n. 2, p. 170-173, 2002.

HINE, R. B.; ARAGAKI, M. Influence of soil temperature on a crown rot disease of parsley caused by Phytophthora parasitic. Phytopathology, Saint Paul, v. 53, n. 5, p. 11131114, 1963.

KILPATRICK, R. A.; JOHNSON, H. W. Sporulation of Cercospora species on carrot leaf decoction agar. Phytopathology, Saint Paul, v. 46, n. 2, p. 180-181, 1956.

LILLY, V. G.; BARNETT, H. L. Physiology of the fungi. 3. ed. New York: McGraw-Hill Book, 1951. 464 p.

LUKENS, R. J. Photo-inhibition of sporulation in Alternaria solani. American Journal of Botany, Saint Louis, v. 50, n. 7, p. 721-724, 1963.

MELO, M. M.; REIS, E. M. Efeito de substratos, luz e sobreposição de papel de filtro na esporulação de Corynespora cassiicola. Summa Phytopathologica, Botucatu, v. 36, n. 3, p. 251-253, 2010.

MORAES, S.; SALGADO, C. L. Influência da luz sobre a esporulação de Cercospora arachidicola Hori. Summa Phytopathologica, Botucatu, v. 4, n. 2, p. 128-135, 1997.

PULZ, P.; MASSOLA, J. R.; NELSON, S. Efeito de meios de cultura e fatores físicos no crescimento e esporulação de Alternaria dauci e A. solani. Summa Phytopathologica, Botucatu, v. 35, n. 2, p. 121-126, 2009.

QUEIROZ, F. M.; MENEZES, M. Efeito de meios de cultura e do regime de luz na esporulação de Cercospora nicotianae. Fitopatologia Brasileira, Lavras, v. 18, n. 4, p. 545-547, 1993.

REIS, E. M.; KIMATI, H. Nota sobre a ocorrência de Cercospora sojina Hara causando mancha foliar olho-derã em soja, no Rio Grande do Sul. O Solo, Piracicaba, v. 65, n. 1, p. 34, 1973.

SHIN, H. D.; BRAUN, U. Notes on Korean Cercosporae and allied genera (II). Mycotaxon, New Orland, v. 58, n. 2, p. 157-166, 1996.

STAVELY, J. R.; NIMMO, J. A. Effects of temperature upon growth and sporulation of Cercospora nicotianae. Phytopathology, Saint Paul, v. 59, n. 2, p. 496-498, 1969.

STRANDBERG, J. O. Isolation, storage, and inoculum production methods for Alternaria dauci. Phytopathology, Saint Paul, v. 77, n. 4, p. 1008-1012, 1987.

TEIXEIRA, H.; CHITARRA, L. G.; ARIAS, S. M. S.; MACHADO, J. C. Efeito de diferentes fontes de luz no crescimento e esporulação in vitro de fungos fitopatogênicos. Ciência Agrotécnica, Lavras, v. 25, n. 6, p. 1314-1320, 2001.

TUITE, J. Plant pathological methods: fungi and bacterial. 5. ed. Minneapolis: Burgess Publishing Company, Department of Botany and Plant Pathology, 1969. $239 \mathrm{p}$. 
VEIGA, P.; KIMATI, H. Influência de meios de cultura e regime luminoso na esporulação de Cercospora sojina Hara. Revista Centro Ciências Rurais, Cascavel, v. 4, n. 2, p. 159-164, 1974.
YORINORI, J. T.; KLINGELFUSS, L. H. Novas raças de Cercospora sojina em soja. Fitopatologia Brasileira, Brasília, v. 24, n. 3, p. 509-512, 2000.

YORINORI, J. T. Doenças: In: YORINORI, J. T. (Ed.). Ministério da agricultura. Londrina: IPEAME, 1971. p. 13-16. (Soja no Paraná. Circular, v. 9). 